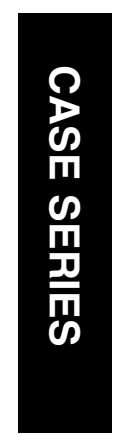

${ }^{1}$ Department of

Ophthalmology

School of Medicine

Federal University of

Uberlândia

Minas Gerais, Brazil

${ }^{2}$ Department of

Ophthalmology

Glaucoma Service

Campinas University-

UNICAMP

São Paulo, Brazil

${ }^{3}$ School of Medicine

Federal University of Mato

Grosso do Sul, Brazil

Correspondence: ES Arcieri

Rua Corcovado

no 155

apto 402 Bairro

Copacabana

CEP 38411-092

Uberlândia Minas Gerais

Brazil

Tel: + 553432559090

Fax: + 553432559090

E-mail: rsaran@triang.com.br

Received: 8 June 2003

Accepted: 6 November

2003

Published online: 16 April

2004

The authors do not have any commercial or propietary interest in the drugs and equipment mentioned in the present article.

Presented as poster at: VII Congresso Internacional de Catarata e Cirurgia Refrativa, São Paulo, Brazil. XV Congresso Brasileiro de Prevenção da Cegueira e Reabilitação Visual, Curitiba, Brazil.

\title{
Subepithelial infiltrates associated to viral keratoconjunctivitis following photorefractive keratectomy
}

\begin{abstract}
Purpose To report three cases of adenoviral keratoconjunctivitis in patients who have undergone photorefractive keratectomy and that just developed subepithelial infiltrates. Methods Description of patients that developed postoperative adenoviral keratoconjunctivitis after photorefractive keratectomy without influence in the final visual outcome.

Results All patients presented adenoviral keratoconjunctivitis 2-3 months after refractive surgery. They developed multiple pinpoint subepithelial infiltrates in six eyes, without haze development. The final uncorrected visual acuity was better or equal to $20 / 30$.

Conclusion Although patients undergoing photorefractive keratectomy might develop severe corneal scarring following ocular infections, such events may follow their natural evolution.
\end{abstract}

Eye (2004) 18, 1010-1012. doi:10.1038/sj.eye.6701377

Published online 16 April 2004

Keywords: inflammation; excimer laser; cornea; photorefractive keratectomy; keratoconjunctivitis

\section{Introduction}

It has been shown that tiny portions of corneal tissue can be accurately removed by photorefractive keratectomy (PRK), apparently without causing any complications, therefore being regarded as an effective and safe method for the correction of low-to-moderate refractive errors. ${ }^{1}$
ES Arcieri ${ }^{1,2}$, RS Arcieri ${ }^{3}$, ET França ${ }^{1}$ and

FJ Rocha ${ }^{1}$
One of the most common complications following PRK is the loss of corneal transparency secondary to corneal wound healing, which has been clinically observed as subepithelial reticular opacities, and commonly referred to as haze. ${ }^{2-4}$ Haze after PRK tends to be maximum at 1-6 months after treatment with progressive resolution up to 18 months after surgery, ${ }^{5}$ although it can be followed by myopic regression. ${ }^{6,7}$ Some investigators have reported haze with a late onset after PRK, which has been noticed in a small number of individuals usually starting between 4 months and 1 year after PRK. ${ }^{2,8}$

Factors unrelated to surgery, such as ultraviolet light exposure, pre-existing corneal surface disorders, and oral contraceptive use have been implicated in more severe haze and regression. ${ }^{7}$ Although several types of ocular trauma in patients undergoing PRK can be related to the development of central cornea opacification, ${ }^{9}$ including viral

keratoconjunctivitis, this outcome is not always seen.

In this study, we report three cases of patients undergoing PRK who presented with adenoviral keratoconjunctivitis in the postoperative period and developed only subepithelial opacities, typical of this pathology, without haze or myopic regression.

\section{Case reports}

All patients underwent PRK using a VISX 20/20 excimer laser (VISX, Santa Clara, CA, USA) after mechanical de-epithelization of the cornea, with total correction of refraction under cycloplegia within a treatment zone of $6 \mathrm{~mm}$ in diameter. 
Each eye reepithelized within 4 days after surgery. Postoperatively they received soft bandage contact lenses until complete healing, tobramycin and dexamethasone drops q.i.d. for 7 days, followed by topical $1 \%$ predinisolone acetate q.i.d. for another 7 days, at which time $0.1 \%$ fluorometholone drops were initiated q.i.d. with gradual withdrawal during 10 weeks.

\section{Case 1}

A 27-year-old man without any pathological background, except for refractive error, underwent simultaneous bilateral refractive surgery with no complications. Preoperative cyclopegic refractions were $-4.25-1.00 \times 30^{\circ}$ in the right eye (OD) and -4.75 $-0.50 \times 175^{\circ}$ in the left eye (OS). Best spectacle-corrected visual acuity (VA) was 20/20 in both eyes (BE). Central pachometry was $514 \mu \mathrm{m}$ OD and $512 \mu \mathrm{m}$ OS.

At 3 months after surgery, the patient's VA without correction $\left(\mathrm{VA}_{\mathrm{w} / \mathrm{c}}\right)$ was 20/20 OD and 20/30 OS, with mild haze in OE. At that time, the patient presented with adenoviral keratoconjunctivitis and was prescribed topical dexamethasone q.i.d., reduced by one drop per week. At 4 months after PRK, the patient's $\mathrm{VA}_{\mathrm{w} / \mathrm{c}}$ was 20/20 OD and 20/25 OE, with subepithelial infiltrates in the visual axis of $\mathrm{BE}$. At 5 months after surgery, the patient's $\mathrm{VA}_{\mathrm{w} / \mathrm{c}}$ was 20/25 in each eye, and subepithelial infiltrates persisted only in the central region.

\section{Case 2}

A 25-year-old man without any pathological background, except for refractive error, underwent simultaneous bilateral refractive surgery with no complications. Preoperative cyclopegic refractions were $-2.25-0.75 \times 20^{\circ}$ OD and $-2.25-0.25 \times 180^{\circ}$ OS. Best spectacle-corrected VA was 20/20 BE. Central pachometry was $586 \mu \mathrm{m}$ OD and $568 \mu \mathrm{m}$ OS.

At 2 months after surgery, the patient's uncorrected VA was 20/20 in each eye with no biomicroscopic changes. At $2 \frac{1}{2}$ months after PRK, the patient presented with adenoviral keratoconjunctivitis in $\mathrm{BE}$ and was prescribed topical $0.1 \%$ fluorometholone q.i.d. After 1 month, the uncorrected VA was 20/25 OD and 20/50 OS, with the presence of subepithelial infiltrates more intense in OS. Topical $0.1 \%$ fluorometholone t.i.d. was prescribed for an additional 30 days. At 6 months after surgery, the patient's $\mathrm{VA}_{\mathrm{w} / \mathrm{c}}$ was 20/20 OD and 20/25 OS, with the presence of mild subepithelial infiltrates in the central visual axis in BE.

\section{Case 3}

A 36-year-old man without any pathological background, except for refractive error, underwent simultaneous bilateral refractive surgery with no complications. Preoperative cyclopegic refractions were $-3.00-0.75 \times 75^{\circ} \mathrm{OD}$ and $-3.00-0.75 \times 180^{\circ} \mathrm{OS}$. Best spectacle-corrected VA was 20/20 BE. Central pachometry was $522 \mu \mathrm{m}$ OD and $517 \mu \mathrm{m}$ OS.

At 2 months after surgery, the patient's uncorrected VA was 20/20 in each eye with no biomicroscopic changes. At 3 months after PRK, he presented with adenoviral keratoconjunctivitis in BE. The uncorrected VA decreased to 20/30 OD and 20/50 OS. The patient was prescribed topical $1 \%$ predinisolone acetate q.i.d. and topical ofloxacin q.i.d.

At 2 days after the onset of keratoconjunctivitis, the patient developed punctate epithelial keratitis (Figure 1) and pseudomembranous lesion in the inferior tarsal conjunctiva in OD, with decreased uncorrected VA to 20/ 100 OD. At 15 days after the beginning of the symptoms, VA improved to 20/40. Slit-lamp examination disclosed subepithelial infiltrates in the central visual axis in OD (Figure 2). The OS had only a mild, short-lasting punctate keratitis. Eyedrops were substituted for topical $0.1 \%$ fluorometholone q.i.d., reduced by one drop per week.

At 8 months after surgery, the patient's $\mathrm{VA}_{\mathrm{w} / \mathrm{c}}$ was 20/ 30 OD and 20/20 OS, with the presence of subepithelial infiltrates in the central and paracentral area in OD and outside the visual axis in OS. At 2 years after PRK, uncorrected VA was 20/20 in each eye, with the persistance of mild subepithelial infiltrates.

\section{Discussion}

Adenovirus is one of the most frequent etiologies of keratoconjunctivitis with an acute onset. ${ }^{2}$ Classic

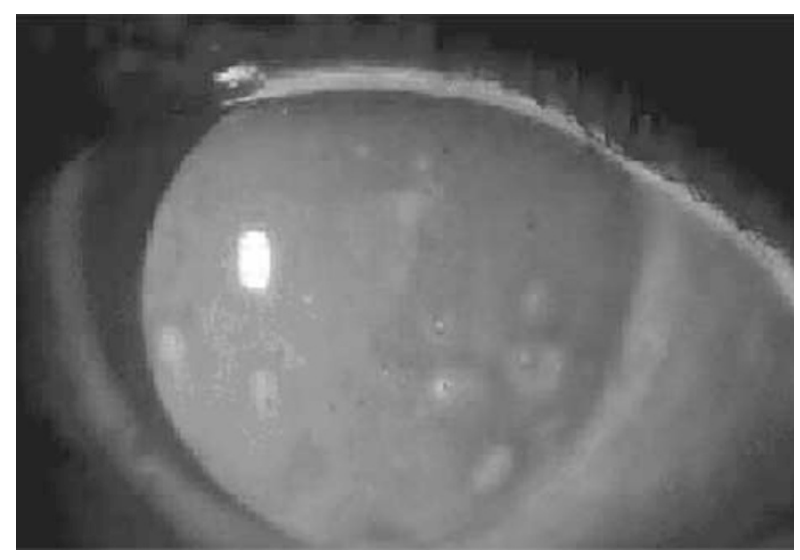

Figure 1 Photograph of right eye of patient 3 showing punctate epithelial keratitis staining with fluorescein. 


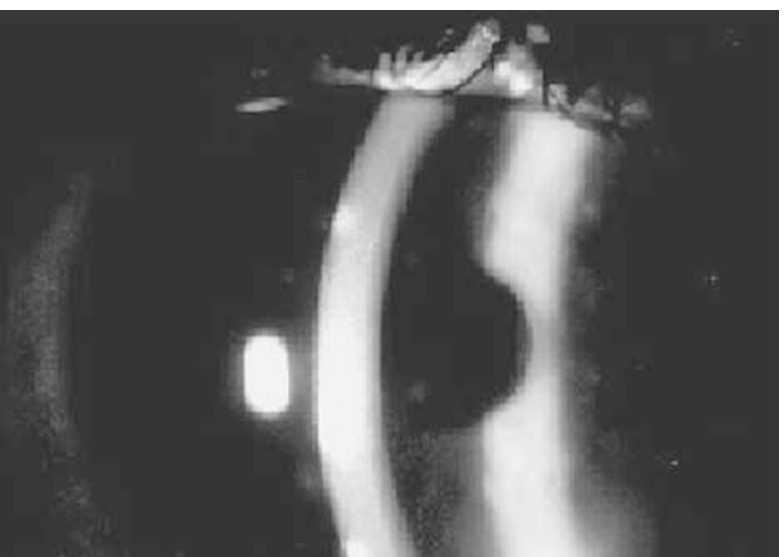

Figure 2 Slit-beam appearance of the subepithelial infiltrates in the central visual axis of right eye-patient 3 .

adenovirus keratitis presents with subepithelial corneal infiltrates, which develop 1-2 weeks after acute follicular conjunctivitis and associated punctate epithelial keratitis. ${ }^{10}$ Although other viruses can produce subepithelial infiltrates with a similar picture and cannot be ruled out, ${ }^{2}$ our three patients - on clinical grounds - most certainly had adenoviral keratoconjunctivitis.

The subepithelial infiltrates resulting from adenoviral keratoconjunctivitis are thought to represent a delayed hypersensitivity immune response to viral antigens in the corneal stroma. ${ }^{11}$ The infiltrates are corticosteroidsensitive and often resolve in weeks to months after initial presentation. ${ }^{12}$

It appears that the direct contact between epithelial cells and corneal stroma triggers abnormal corneal wound healing after PRK. ${ }^{3,13}$ Hyperactive keratocytes or loss of Bowman's layer ${ }^{2}$ may explain the unusual response after adenoviral keratoconjunctivitis in these patients. Campos et $a l^{9}$ and Pineda and Talamo ${ }^{2}$ reported cases of patients who had undergone PRK and presented with late-onset corneal haze following adenoviral keratoconjunctivitis. In agreement with Pineda and Talamo, ${ }^{2}$ patients who undergo PRK may be at greater risk for loss of VA following viral keratoconjunctivitis, due to secondary changes such as persistent subepithelial scarring, anterior stromal fibrosis within the PRK treatment zone, irregular corneal topographic changes, or myopic regression, all of which could influence final visual outcome.

Our three cases developed only subepithelial infiltrates, which did not respond clinically to topical corticosteroids, unlike in classic cases of adenoviral keratoconjunctivitis, in agreement with findings by
Pineda and Talamo. ${ }^{2}$ However, late-onset corneal haze, myopic regression, impairment of VA, and irregular corneal topographic changes were not observed in these patients. They presented with final VA without correction greater than or equal to $20 / 30$.

The post-PRK inflammatory event responsible for the potentiation of the corneal response is probably related to an unknown mechanism, which can present different clinical changes in each case. Although patients undergoing PRK might develop severe corneal scarring following ocular infections, such events may follow their natural course.

\section{References}

1 Bechara SJ, Kara-José N. Laser em Cirurgia de Córnea. In: Belfort Jr R, Kara-José N (eds) Córnea Clínica-Cirúrgica. Roca: São Paulo, 1996, pp 593-599.

2 Pineda R, Talamo JH. Late onset of haze associated with viral keratoconjunctivitis following photorefractive keratectomy. J Refract Surg 1998; 14: 147-151.

3 Marshall J, Trockel SL, Rothery S, Krueger RR. Long term healing of the central cornea after photorefractive keratectomy using an excimer laser. Ophthalmology 1988; 95: 1411-1421.

4 Seiler T, Holshbach A, Derse M, Jean B, Genth U. Complications of photorefractive keratectomy with the excimer laser. Ophthalmology 1994; 101: 153-160.

5 Lohman C, Gartry D, Kerr Muir MG, Marshall J. Haze in photorefractive keratectomy: its origins and consequences. Lasers Light Ophthalmol 1991; 4: 15-34.

6 Gartry DS, Kerr Muir MG, Marshall J. Excimer laser photorefractive keratectomy; 18-month follow-up. Ophthalmology 1992; 99: 1209-1219.

7 Corbett MC, O'Brart DPS, Warburton FG, Marshall J. Biologic and environmental factors for regression after photorefractive keratectomy. Ophthalmology 1996; 103: 1382-1391.

8 Lipshitz I, Loewenstein A, Varssano D, Lazar M. Late onset corneal haze after photorefractive keratectomy for moderate and high myopia. Ophthalmology 1997; 104: 369-374.

9 Campos M, Takahashi R, Tanaka H, Chamon W, Allemann $\mathrm{N}$. Inflammation-related scarring after photorefractive keratectomy. Cornea 1998; 17: 607-610.

10 Chodosh J, Miller D, Stroop WG, Pflugfelder SC. Adenovirus epithelial keratitis. Cornea 1995; 14: 167-174.

11 Jones BR. The clinical features of viral keratitis and a concept of their pathogenesis. Proc Royal Soc Med 1958; 51: 13-20.

12 Laibson PR. Ocular adenoviral infections. Ophthalmol Clin 1984; 24: 49-64.

13 Meyer JC, Stulting RD, Thompson KP, Durrie DS. Late onset of cornea scar after excimer laser photorefractive keratectomy. Am J Ophthalmol 1996; 121: 529-539. 